\title{
The CSIRO-Mk3.6.0 Atmosphere-Ocean GCM: participation in CMIP5 and data publication
}

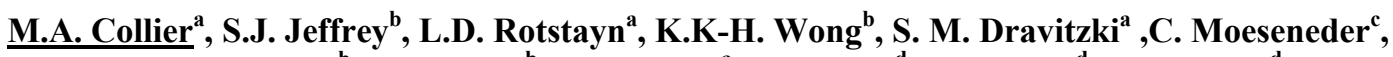 \\ C. Hamalainen ${ }^{b}$, J.I. Syktus ${ }^{b}$, R. Suppiah ${ }^{a}$, J. Antony ${ }^{d}$, A. EI Zein ${ }^{d}$ and M. Atif ${ }^{d}$ \\ ${ }^{a}$ The Centre for Australian Weather and Climate Research, CSIRO Marine and Atmospheric Research, \\ Aspendale, Victoria \\ ${ }^{b}$ The Queensland Climate Change Centre of Excellence, Ecosciences Precinct, Dutton Park, Queensland \\ ${ }^{c}$ CSIRO Marine and Atmospheric Research, Ecosciences Precinct, Dutton Park, Queensland \\ ${ }^{d}$ National Computation Infrastructure National Facility, Australian National University, Australian Capital \\ Territory \\ Email:mark.collier@csiro.au
}

\begin{abstract}
The participation of the CSIRO-Mk3.6.0 Atmosphere Ocean Global Climate Model (AOGCM) in the Coupled Model Intercomparison Project Phase 5 (CMIP5) is a joint initiative between the Queensland Climate Change Centre of Excellence and the Commonwealth Scientific and Industrial Research Organisation (CSIRO). It now has approximately 10 research and support scientists working on this project which first began in 2009. This on-going project consists of the following four main components:
\end{abstract}

- A model design and testing period to ensure that the model had acceptable configuration for participation in CMIP5, in particular, exhibiting a realistic present-day climate and a stable preindustrial climate;

- A model integration phase where CMIP5 experiments were performed. These were to include the so-called "core" experiments plus a number of "tier1" and "tier2" experiments, which will constitute a significant submission to CMIP5 and to address local climate modelling needs and applications;

- Post-processing of the raw CSIRO-Mk3.6.0 model output into internationally recognised and standardized CMIP5 form; and

- Quality control and publication phase of the CSIRO-Mk3.6.0 data to ensure entry into the Earth System Grid (ESG) Federation, allowing it to be disseminated to the CMIP5 international community.

In this paper the four phases of this climate modelling project will be discussed in detail. The main emphasis is to make potentially interested researchers aware of the CSIRO-Mk3.6.0 climate model submission and to elucidate the range and features of the datasets that are now available. The CMIP5 datasets are being hosted on the ESG which consists of international data nodes and gateways, including Australia's own node hosted by the National Computing Infrastructure (NCI) National Facility in Canberra. A key outcome of our efforts is the generation of over 150, mostly high priority, uniquely defined parameters from the list of requested model output to understand climate processes and also produce new climate change projection data for impact assessment. Some preliminary results of the CSIRO-Mk3.6.0 model are presented to illustrate the usefulness of this dataset in this research area.

Keywords: CMIP5, AR5, AOGCM, climate change simulations, Earth System Grid 


\section{INTRODUCTION}

The partnership between the Commonwealth Scientific and Industrial Research Organisation (CSIRO) and Queensland Climate Change Centre of Excellence (QCCCE) in the Coupled Model Intercomparison Project Phase 5 (CMIP5) has quite possibly delivered the largest and scientifically most comprehensive set of Atmosphere-Ocean Global Climate Model data ever generated in Australia. Although there is a need to make these datasets available to climate analysts around the world, there is a particular need in Australia for a comprehensive set of climate experiments. This will facilitate research into the important drivers of Australian climate. CSIRO has participated in the CMIP modelling activity before (Collier et al., 2007) however the data volume is an order of magnitude greater than the previous model intercomparison (Collier et al., 2011a,b).

\section{WHAT IS CMIP5?}

CMIP5 is an internationally coordinated effort to use state-of-the-art Global Climate Models (GCMs) and Earth System Models (GCMs which include interactive carbon and/or ocean biogeochemistry) to perform a set of predefined experiments (Taylor et al., 2011). Scientific publications arising from analysis of CMIP5 data will be used to assess climate change science, most directly through the publication of the Intergovernmental Panel on Climate Change (IPCC) Fifth Assessment Report (AR5) due to be published in 2013. CMIP5 has taken datasets from a range of internationally recognised climate models and has built an archive that can be readily analysed because all datasets have a consistent format. The strict formatting requirements also necessitated an unprecedented approach to quality control (see Sec. 5 for details). To end-users, the CMIP5 data archive will provide an efficient means for locating and obtaining datasets for local analysis. CMIP5 datasets are being made publicly available via the Earth System Grid (ESG) federation of services. Users will identify the desired dataset(s) through a series of ESG gateways and will then be directed to the appropriate data node to download the desired dataset(s) to their local machine.

\section{CSIRO-MK3.6.0 AOGCM}

The CSIRO-Mk3.6.0 model, hereafter called Mk3.6, is an upgrade from the CSIRO-Mk3.5 GCM (Gordon et al., 2010). Details of the model are given by Rotstayn et al. (2010). The atmospheric component has a horizontal resolution of approximately $1.9^{\circ} \times 1.9^{\circ}$ and every atmospheric grid-point is coupled to two ocean grid-points. This enhanced north-south resolution in the ocean component is expected to increase the capacity for the ocean to simulate important tropical and extra-tropical seasonal interactions. The atmosphere has 18 vertical levels whereas the ocean has 30 levels with most found in the upper $1500 \mathrm{~m}$. By far the most important improvement of the Mk3.6 model from its predecessor is the inclusion of an interactive aerosol scheme that also required an update to the radiation scheme used in the model (Rotstayn et al., 2010). This allows for the investigation of the impact of a number of aerosol agents on climate. For example, a recent study by Rotstayn et al. (2011a) investigated the impact of mineral dust on Australian rainfall by turning it on and off in two experiments. The study found that an accurate simulation of the El Niño-Southern oscillation (ENSO)-rainfall relationship over Australia might require realistic representation of processes associated with sources and deposition of Australian dust.

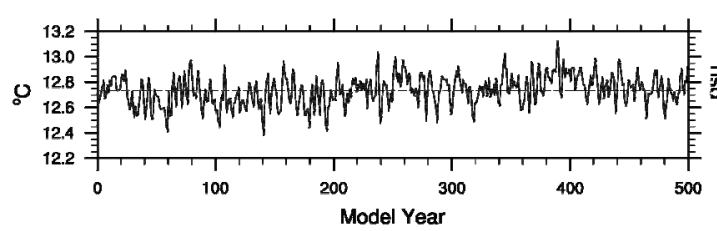

Figure 1. Global average surface air temperature $\left({ }^{\circ} \mathrm{C}\right)$ for the CSIRO-Mk3.6.0 preindustrial control experiment. The dashed line is the 500 year average.

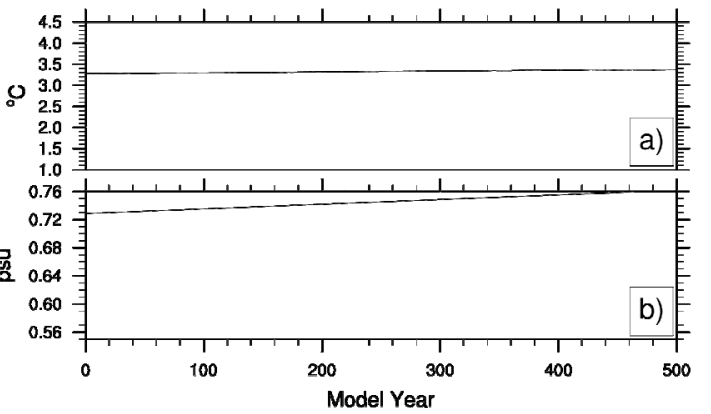

Figure 2. Global average volume weighted a) ocean potential temperature $\left({ }^{\circ} \mathrm{C}\right)$ and b) salinity (psu-34.0) for the CSIRO-Mk3.6.0 preindustrial control experiment.

To have confidence in a climate model's ability to realistically simulate present and future climate conditions it is necessary for it to be able to respond in a satisfactory manner when driven by pre-industrial (year 1850) forcings. An important indicator of this is the stability of the model solution which includes negligible drift in important climate indices and one devoid of irregular behavior. Figure 1 shows globally averaged annual 
surface temperature from the pre-industrial control experiment, which appears to be stable during the 500 year long experiment. Figure 2 shows the ocean potential temperature and salinity (practical salinity units). The ocean temperature drift in the $\mathrm{Mk} 3.6$ is $0.02^{\circ} \mathrm{C} /$ century, which is comparable to other coupled climate models. The salinity drift is also and indicates the global precipitation and evaporation are not perfectly balanced in the model, at least on these time-scales.

\section{CSIRO-MK3.6.0 MODEL INTEGRATION}

In this section we describe the computing facilities that were used for the integration of the Mk3.6 AOGCM for CMIP5. In addition the list of experiments will be presented with essential details on their characteristics, including their name, the number of ensembles and the output model years.

\subsection{QCCCE Computing Facility}

The complete set of Mk3.6 experiments was run on the Queensland Government Department of Environment and Resource Management's High Performance Computing facilities. Original experimentation began in January 2010 and most of the key experimentation finished in July 2011, however, the long model integrations out to the year 2300 are expected to be finished in late 2011. Although the computing resources were adequate for this project the model output needed to be transferred to the National Computing Infrastructure (NCI) National Facility (NF) in Canberra for data hosting.

The CMIP5 experiments conducted with the Mk3.6 climate model are listed in Table 1. Most of the experiments were performed using a fully coupled (AOGCM) whereas some with an atmosphere/land/sea-ice only (AGCM). See http://cmip-pcmdi.llnl.gov/cmip5/docs/Taylor_CMIP5 design.pdf $\quad$ and http://cmippcmdi.llnl.gov/cmip5/docs/cmip5_data_reference_syntax.pdf for details of experimental design and on standard naming conventions.

Table 1. CSIRO-Mk3.6.0 CMIP5 experiments. See text for details. Notes: ${ }^{\dagger}$ ensemble members 1-3 are extended to 2300; ${ }^{\dagger \dagger}$ ensemble members 2-12 are 5 years in length consistent with the CMIP5 specification; and ${ }^{\dagger \dagger}$ experiment commenced in 1950 as ozone changes prior to 1950 were considered negligible.

\begin{tabular}{|l|l|l|l|l|}
\hline Experiment & CMIP5 Experiment & Type & Ensemble size & Years \\
\hline piControl & 3.1 & AOGCM & 1 & $1-500$ \\
\hline historical & 3.2 & AOGCM & 10 & $1850-2005$ \\
\hline amip & 3.3 & AGCM & 10 & $1979-2009$ \\
\hline midHolocene & 3.4 & AOGCM & 1 & $1-100$ \\
\hline rcp45 & 4.1 & AOGCM & 10 & $2006-2100^{\dagger}$ \\
\hline rcp85 & 4.2 & AOGCM & 10 & $2006-2100^{\dagger}$ \\
\hline rcp26 & 4.3 & AOGCM & 10 & $2006-2100$ \\
\hline rcp60 & 4.4 & AOGCM & 10 & $2006-2100$ \\
\hline 1pctCO2 & AOGCM & 1 & $1-140$ \\
\hline sstClim & 6.1 & AGCM & 1 & 30 \\
\hline sstClim4xCO2 & $6.2 \mathrm{a}$ & AGCM & 1 & 30 \\
\hline abrupt4xCO2 & $6.2 \mathrm{~b}$ & AOGCM & 12 & $1-150^{\dagger \dagger}$ \\
\hline sstClimAerosol & 6.3 & AGCM & 1 & $1-30$ \\
\hline sstClimSulfate & $6.4 \mathrm{a}$ & AGCM & 1 & $1-30$ \\
\hline historicalNat & $6.4 \mathrm{~b}$ & AOGCM & 10 & $1850-2012$ \\
\hline historicalGHG & 7.1 & AOGCM & 10 & $1850-2005$ \\
\hline historicalAnt & 7.2 & AOGCM & 10 & $1850-2005$ \\
\hline historicalNoOz & $7.3 \mathrm{a}$ & AOGCM & 10 & $1950-2012^{\dagger \dagger \dagger}$ \\
\hline historicalNoAA & $7.3 \mathrm{~b}$ & AOGCM & 10 & $1850-2005$ \\
\hline historicalAA & $7.3 \mathrm{c}$ & AOGCM & 10 & $1850-2012$ \\
\hline historicalAntNoAA & $7.3 \mathrm{~d}$ & AOGCM & 10 & $1850-2012$ \\
\hline & $7.3 \mathrm{e}$ & & \\
\hline
\end{tabular}

\section{POST-PROCESSING INTO CMIP5 FORM}

The model development and experimentation was a significant challenge: Mk3.6 is the culmination of over 30 years of model development (Smith, 2007). Once the experimentation was complete, the post-processing and publishing cycles also required a substantial amount of work and data processing. Post-processing of model

1 This experiment was designed to isolate the effect of Asian aerosols, in the manner of Rotstayn et al. (2007). 
output was done using the Coupled Model Output Rewriter (CMOR, http://www2-pcmdi.llnl.gov/cmor), and publishing of model data was partially automated by the Earth System Grid data hosting infrastructure.

CMOR is a library that can be used to reformat datasets to a standard prescribed in user-defined tables. By adopting CMOR, the task of reformatting the raw model output to CMIP5 specifications was reduced to writing customised software to load the raw datasets and perform any required derivations or modifications of data. The model data was converted to CMIP5 form using CMOR format-specification tables provided by CMIP5. In addition to reducing the complexity of the post-processing task, the use of CMOR is also expected to improve the quality of the data because CMOR: (i) performs some rudimentary error checking; and (ii) automatically formats the metadata to CMIP5 standards.

The in-house software package can become extremely complicated and sophisticated in itself, as it has to consider technical issues associated with the raw model output and supply the necessary objects to CMOR. Necessary inputs can be simple text strings like the institution name but could also involve complex calculations, for example the derivations of parameters or interpolation from model hybrid coordinates to standard pressure levels.

\section{QUALITY CONTROL AND PUBLISHING ON THE NCI NF ESG}

This section gives details of the Quality Control (QC) approach taken to ensure that the Mk3.6 model output satisfy the CMIP5 standard. An explanation of how the final submitted data were published is also provided.

\subsection{The $Q C$ and $Q C W r a p p e r$ utilities}

One of the most significant shortcomings of the previous activity CMIP3 was the inadequate level of QC conducted on datasets. CMIP5 has a range of QC Levels (QCLs) which are performed at different stages of the post-processing and publishing cycle. By adopting the CMOR interface QCL1 and QCL2 standards are essentially achieved (see http://purl.org/org/cmip5/qc for background information). For more comprehensive checking, the QC tool was used to check all Mk3.6 datasets that were submitted. QC uses a wrapper to impose project-specific requirements; in this case the CMIP5 wrapper was used. When examining a file, QC checks the time coordinate, metadata and data block. The data are scanned to detect values that are missing or replicated, and some statistical properties, such as the global maximum, minimum, mean and standard deviation are computed. While the information from the QC tool is very useful, it is still nevertheless at the discretion of the modeling centre to act on any warnings or errors provided. One extremely useful output from the QC tool is a NetCDF file containing the global mean and standard deviation for each time slice in the input file that was examined. Plotting the mean and standard deviation can be useful in detecting gross errors in the model data and/or processing system. While there may be hundreds of plots for each experiment, these can be scanned through quite quickly. Final QCL3 checks will eventually be performed by the ESG community on the archived datasets allowing the allocation of a Digital Objective Identifier (DOI) in essence giving the datasets persistence and citable credentials in the digital environment.

\section{SIMULATNG PRESENT CLIMATE}

In this section we will present some results based on annual average conditions, particularly focusing on near (2m) surface air temperature and rainfall. In the future we expect to expand this work focusing on seasonally based temperature, mean sea-level pressure and rainfall projections over Australia.

By the end of August 2011 the processed output from the CSIRO-Mk3.6.0 model for a number of key CMIP5 experiments had been published on the NCI ESG gateway. It is expected that the research community both in Australia and abroad will undertake extensive analysis of these datasets. Prior to peer-review publications, preliminary results based on the raw model output have been published elsewhere (see for example, Syktus et al. 2011).

In this section we present some results based on annual average conditions, particularly focusing on near $(2 \mathrm{~m})$ surface air temperature and rainfall.

\subsection{GLOBAL TEMPERATURE RESPONSE}

The model simulated global average near-surface air temperature for the period 1850-2055 and observed (Brohan et al., 2006) data from 1850 to 2010 are shown in Figure 3. The data are presented as anomalies relative to the $1850-1879$ base period. The results for four historical experiments are presented: (i) the historical run with all forcings extended to 2100 by using forcing data from Representative Concentration Pathway (RCP) 4.5 (HIST/RCP4.5); (ii) natural forcings only (NAT); (iii) greenhouse gas forcings only (GHG); and (iv) anthropogenic aerosol forcings only (AA). The NAT, GHG and AA experiments are driven by the observed values for the relevant forcing (natural, 
greenhouse gases and anthropogenic aerosols, respectively), with all other forcings held constant at pre-industrial (1850) levels. All model experiment data are based on a 5 member ensemble average. The HIST experiment shows the best agreement with the observations, as also seen in earlier simulations that include aerosol forcing.

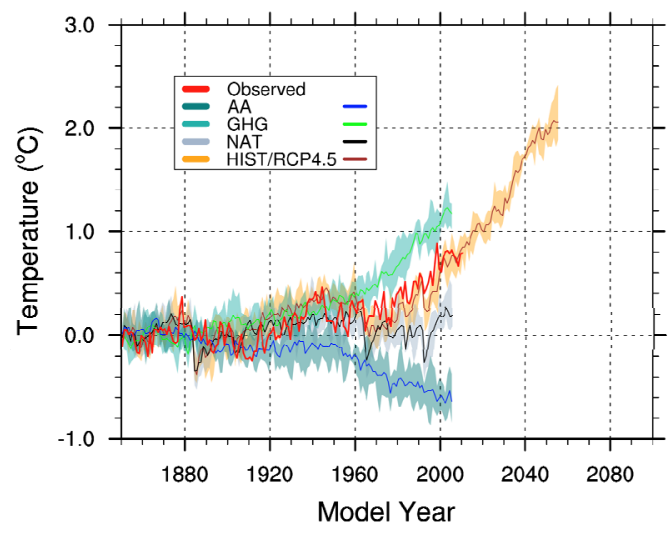

Figure 3. Global average surface air temperature $\left({ }^{\circ} \mathrm{C}\right)$ for four CSIRO-Mk3.6.0 experiments and HadCRUT observations. Filled areas show the range based on the 5 member ensemble and solid lines are ensemble means.
Table 2. Summary of statistics for near surface air temperature $\left(T_{\text {sc }}\right)$ and annual average precipitation $\left(P_{r}\right)$ for the period 1980-2005 for the all-forcings (HIST) experiment 5 member ensemble. Average (ave), standard-devation (sd), root-mean-square (rms) error and pattern correlation (corr) are shown. Minimum and maximum ensemble values are shown by subscripts min and max respectively.

Observations have been interpolated onto the model grid for calculating these statistics. AWAP observational values are shown in parentheses.

\begin{tabular}{|l|l|l|l|l|l|l|}
\hline & $\begin{array}{l}\text { ave } \\
\left({ }^{\circ} \mathrm{C}\right)\end{array}$ & ave $_{\min }$ & ave $_{\max }$ & sd & rms & corr \\
\hline $\mathbf{T}_{\mathbf{s c}}$ & $\begin{array}{l}21.02 \\
(22.04)\end{array}$ & 20.96 & 21.13 & 0.066 & 1.52 & 0.95 \\
\hline $\mathbf{P}_{\mathbf{r}}$ & $\begin{array}{l}1.37 \\
(1.30)\end{array}$ & 1.31 & 1.40 & 0.036 & 0.58 & 0.78 \\
\hline
\end{tabular}

\subsection{PRESENT DAY CLIMATE AND ATTRIBUTION STUDY}

The model simulated and observed AWAP (Australian Water Availability Project, Jones et al., 2009) nearsurface air temperature and precipitation for Australia are shown in Figure 4. The 5 member ensemble mean for the period 1980-2005 is presented, with the ensemble standard deviation indicated by hatching. Regions exhibiting a relatively high standard deviation indicate a wide range in the ensemble members, indicating the potential for more uncertainty in the ensemble mean due to different forcings. A comparison of spatial patterns of simulated temperature for the HIST experiment (Figure 4a) and observations (Figure 4e) indicates the Mk3.6 model reproduces the observed pattern, although the model underestimates the mean in the south and continental interior. The historical experiment driven only by natural forcings (NAT) (Figure 4b) shows slightly lower temperatures compared to the all forcings experiment (Figure 4a), while the experiment driven only by greenhouse gases (GHG) (Figure 4c) overestimates the temperature over the continent. In contrast, the experiment driven only by anthropogenic aerosols (AA) (Figure 4d) slightly underestimates the observed pattern, consistent with the net cooling effect expected of such aerosols. Maps showing the differences between the results of the various attribution experiments would enable greater differentiation between the impacts of the various drivers, and will be the topic of further investigation. Standard deviations based on ensemble members are higher over marginal areas of southeast and central northwest.

The model simulated precipitation is shown by panels $\mathrm{f}-\mathrm{j}$ of Figure 4 indicating good agreement with the observed spatial pattern, although there appears to be a dry bias, particularly in the south-west and south-east. It should be noted that the annual average rainfall does not reflect the important characteristics of the seasonal rainfall distribution and therefore an analysis of the seasonal rainfall distribution will be required for a better assessment of model skill in simulating the Australian rainfall.

An analysis of attribution experiments can provide important assessment potential roles of various climate forcing factors that affect Australian climate. A recent study by Rotstayn et al (2011b) provides an insightful example of the technique.

The model performance in the Australian region for the all-forcings HIST experiment is summarised in Table 2. The ensemble mean near surface air temperature is $21.03{ }^{\circ} \mathrm{C}$ for the period $1980-2005$, compared to an observed value of $22.04{ }^{\circ} \mathrm{C}$. The root mean square error is $1.52{ }^{\circ} \mathrm{C}$ and the pattern correlation is 0.95 . The ensemble mean annual average precipitation is $1.37 \mathrm{~mm}$ /day for the period 1980-2005, compared to an observed value of 1.30 $\mathrm{mm} /$ day. The root mean square error is $0.58 \mathrm{~mm} /$ day and the pattern correlation is 0.78 . The statistics for both 
near surface air temperature and precipitation indicate sound model performance using the demerit point system of Suppiah et al. (2007). Standard deviations based on the 5-member ensemble are higher over central and eastern Australia.
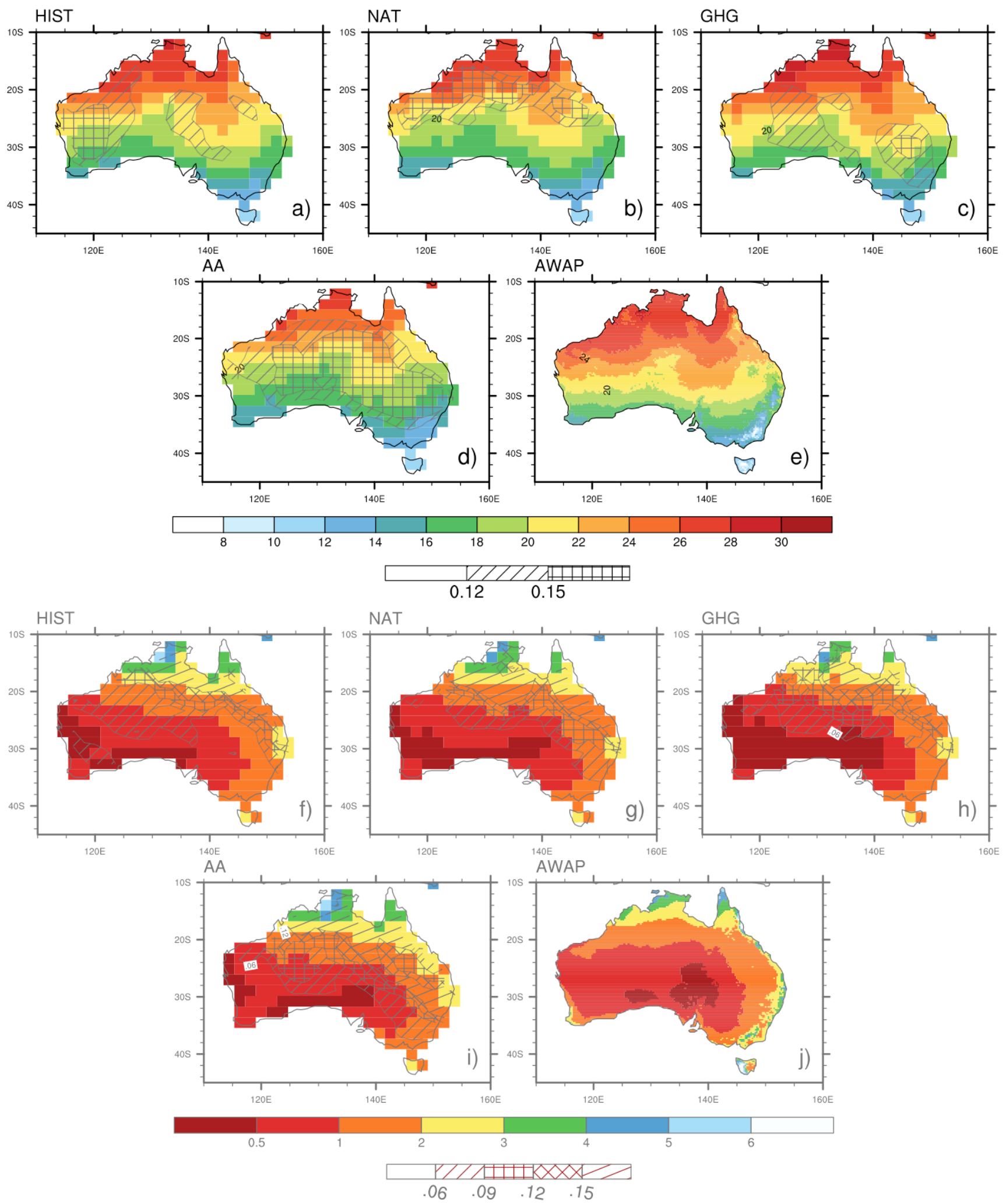

Figure 4. Annual average near surface air temperature (panels a-e, ${ }^{\circ} \mathrm{C}$ ) and precipitation (panels f-j, $\mathrm{mm}$ /day) simulated by the CSIRO-Mk3.6.0 and observations (AWAP). The hatching indicates the 5 member ensemble standard deviation $\left({ }^{\circ} \mathrm{C}\right.$ and $\mathrm{mm} / \mathrm{day}$, respectively). HIST, NAT, GHG, AA refer to experiments historical, historicalNat, historicalGHG and historicalAA from Table 1. 


\section{DISCUSSION AND CONCLUSIONS}

In this paper we have described the experimentation, post-processing, quality control and publishing phases involved in preparing the Mk3.6 datasets for submission to the CMIP5 data archive. The most novel aspects of the submission are the relatively large ensemble sizes used in the experiments, and the range of historical experiments undertaken. The attribution experiments will provide a rich dataset for elucidating the key drivers of change in Australia's climate. It is envisaged that the submission will be used in many climate change detection and attribution studies that will be used to prepare the IPCC $5^{\text {th }}$ Assessment Report, due for release in 2013. Moreover, the datasets will be of great interest to the Australian scientific community well beyond AR5, providing the agencies that supported this work with a significant return on investment. Our early analysis suggests that the Mk3.6 model soundly simulates present day screen temperature and precipitation over Australia, lending credence to the future projections generated by the model.

\section{REFERENCES}

Brohan, P., J. J.Kennedy, I. Harris, S. F. B. Tett, and P. D. Jones (2006), Uncertainty estimates in regional and global observed temperature changes: A new data set from 1850, J. Geophys. Res., 111, D12106, doi:10.1029/2005JD006548

Collier, M.A., Dix, M.R. and A.C. Hirst (2007). CSIRO Mk3 Climate System Model and Meeting the Strict IPCC AR4 Data Requirements. MODSIM08 Extended Abstract, Christchurch, New Zealand.

Collier, M.A., Jeffrey, S., Dix, M.R., Hirst, A.C and L.D. Rotstayn (2011a). Dealing with and contributing to the CMIP5 data 'tsunami' and beyond from an Australian perspective. Greenhouse 2001, Cairns, 4-18 ${ }^{\text {th }}$ April 2011.

Collier, M.A., Jeffrey, S. and L.D. Rotstayn (2011b). The latest Australian CMIP climate model submission. BAMOS, October edition, in press.

Gordon, H.B. and co-authors (2010). The CSIRO Mk3.5 Climate Model. CAWCR Technical Report No. 21, $74 \mathrm{pp}$.

Jones, D. A., Wang, W., and Fawcett, R. (2009) High-quality spatial climate data-sets for Australia, Aust. Meteorol. Oceanogr. J., 58, 233-248.

Rotstayn, L.D., Collier, M.A., Dix, M.R., Feng, Y., Gordon, H.B., O’Farrell, S.P., Smith, I.N. and J.I. Syktus (2010). Improved Simulation of Australian Climate and ENSO-related rainfall variability in a global climate model with interactive aerosol treatment. Int. J. Climatol. 30: 1067-1088. doi: 10.1002/joc.1952.

Rotstayn, L.D., Collier, M.A., Mitchell, R.M., Qin, Y., S.K. Campbell and S. M. Dravitzki (2011a). Simulated enhancement of ENSO-related rainfall variability due to Australian dust. Atmos. Chem. Phys., 11, 6575-6592, doi: 10.5194/acp-11-6575-2011.

Rotstayn, L.D., Jeffrey, S.J., Syktus, J.I., Collier, M.A., Dravitzki, S.M., Hirst, A.C. and K.K-H. Wong (2011b). Have anthropogenic aerosols delayed greenhouse gas-induced changes in Indo-Pacific regional circulation and rainfall? Atmospheric Science Letters, submitted.

Smith, I. (2007). Global climate modelling within CSIRO: 1981 to 2006, Aust. Meteorol. Mag., 56, 153-166.

Suppiah, R., Hennessy, K.J., Whetton, P.H., McInnes, K., Macadam, I, Bathols, J., Ricketts, J. and C.M. Page (2007). Australian climate change projections derived from simulations performed for the IPCC $4^{\text {th }}$ Assessment Report, Aust. Met. Mag., 56, 131-152.

Syktus, J., Wong, K.K-H., Rotstayn, L.D., Jeffrey, S., Zhang, H., Toombs, N.R. and M.A. Collier (2011). Australia's hotter and drier future: Climate change projections using CMIP5 experimental design and the CSIRO Mk3.6 climate model. Greenhouse 2011, Cairns, 4-18 ${ }^{\text {th }}$ April 2011.

Taylor, K.E., Stouffer, R.J. and G.A. Meehl (2011). A Summary of the CMIP5 Experiment Design. Available in electronic form: http://cmip-pcmdi.llnl.gov/cmip5/docs/Taylor_CMIP5_design.pdf. 